\title{
Uncanny sociocultural categories
}

\author{
Jordan R. Schoenherr ${ }^{*}$ and Tyler J. Burleigh ${ }^{2}$ \\ ${ }^{1}$ Department of Psychology, Carleton University, Ottawa, ON, Canada \\ ${ }^{2}$ Department of Psychology, University of Guelph, Guelph, ON, Canada \\ *Correspondence: jordan.schoenherr@carleton.ca \\ Edited by: \\ Marcus Cheetham, University of Zürich, Switzerland \\ Reviewed by: \\ Steven Young, Baruch College, USA
}

Keywords: uncanny valley, cultural artifacts, categorical perception, categorization, social identity, cultural transmission

\section{INTRODUCTION}

Humans are well adapted to their social environments. Experimental evidence suggests that humans are either born with, or quickly learn, the necessary affective and cognitive processes that allow them to recognize others, and to understand their mental states and social behavior. Mori's (1970) proposal of an uncanny valley, which describes affective response as a function of distance from a human category defined by morphological and behavioral features (i.e., human likeness), appears to be a sensible extension of these ideas. Following Mori's initial proposal, the uncanny valley has largely been considered in the context of cultural artifacts such as robotics, prosthetics, toys, and puppets. He associated "healthy people" with the greatest level of familiarity and positive affect, prosthetic hands and corpses with a global negative affective maximum, and bunraku puppets and humanoid robots with intermediate levels of familiarity and positive affect. It is important to note that these cultural artifacts represent the most contemporary features of human societies. The uncanny valley likely depends on extensions of prepotent responses to stimuli via general learning mechanisms (e.g., face recognition; Haxby et al., 2002; Sperber and Hirschfeld, 2004). Empirical studies of the uncanny valley have just begun to explore the authenticity of Mori's proposal.

Contemporary studies examining the uncanny valley hypothesis have drawn heavily on the psychological literature to explain these phenomena. The shift from an account of the uncanny valley based on a dimension of human-likeness to that of categorization and frequency-based exposure (Burleigh and Schoenherr, 2014) suggests that classes of cultural artifacts might provide evidence for the ubiquity of phenomena across cultures and within human history. These social representations can become external representations available to all members of a human group and can thereby increase familiarity and anchor human judgments (Moscovici, 1981). Supporting Mori's initial claim, negative responses are the result of a lack of familiarity (e.g., Burleigh and Schoenherr, 2014) that emerge over the course of development (Lewkowicz and Ghazanfar, 2012) as humans' affective systems have yet to adapt to these artifacts. If the uncanny valley does have a general cognitive basis, then evidence from affective, behavioral, and cognitive paradigms should exist both across cultures as well as within human history. These social representations will consequently affect observers' judgments.

\section{HUMAN AND NON-HUMAN CLASSIFICATION} Folktaxonomies and covert categories

A particularly compelling source of evidence for the uncanny valley comes from research into folktaxonomies. When we encounter an organism, our knowledge of folkbiological categories can cause us to classify stimuli in terms of a species (e.g., "fish") or an ecological niche (e.g., "aquatic habitat") that is available within a folktaxonomic structure. While the preferred level of categorization within these taxonomies differs between cultures (e.g., Rosch et al., 1976; Medin et al., 1997) and expertise (Tanaka and Taylor, 1991; Medin et al., 1997), such taxonomies form the basis for all judgements of category membership. In the context of this work, we suggest that cognitive anthropological research on folktaxonomies has revealed uncanny valley-like phenomena in the form of "covert categories"-categories that cannot be readily placed into a taxonomical structure (e.g., octopus). Covert categories are cognitively isolated from other ontological categories (Berlin, 1974; Atran, 1983). For instance, informants might be able to identify a number of basic-level properties of an octopus, and yet be unable to associate it with a superordinate category (e.g., "fish”). In Berlin et al.'s (1968) study of Tzetal Mayans' folktaxonomies, they found numerous covert groups that did not fall into any of the major lifeform categories (this term is used in the anthropological literature but is equivalent to the superordinate level in the psychological literature; c.f., Brown, 1974). These categories are also associated with aversive responses, such as food prohibitions (Douglas, 1966/2002; Sperber, 1996). For example, Henrich and Henrich (2010) observed that the ambiguity in classifying an octopus as a "fish" or "non-fish" was associated with a food taboo. Douglas (1957) also observed similar outcomes with other ambiguous animals, like the flying squirrel. Such responses to categorically ambiguous stimuli are consistent with the uncanny valley hypothesis.

\section{Anomalies: gods and monsters}

Related to covert categories is the human concern with biological anomalies, gods, and monsters evidenced throughout human history. In many cases, covert categories might be the basis for these ontological categories. As Sperber (1996) 
has pointed out in his discussion of hybrids and monsters, such entities tend to combine features from disparate categories; ranging from the addition of a single feature, such as unicorns which are horses with a horn, to more elaborate amalgams that combine multiple features, such as the Minotaur and Manticore which share features from human and animal categories. Representative of the crosscultural trend are Japanese mythological creatures such as Tsuchigumo, a creature that has the face of a demon, the legs of a spider, and the body of a tiger.

Such mythological creatures might reflect social representations that are the products of cultural transmission. This is evidenced by Mayor's (2001, 2005) study of how ancient peoples classified fossilized creatures. Specifically, Mayor noted that ancient peoples appear to have understood fossils by assimilating them into extant ontological categories. In the absence of a clear understanding the process of fossilization, they would have perceived fossils as the scattered bones of what were believed to be living species. For instance, Mayor (2001) claims that when the fossilized remains of a protoceratops were encountered, in an attempt to account for the presence of these bones, ancients inferred the existence of griffons. Support for her argument is taken from the co-localization of fossils and reported observation of these creatures in ancient times. To ancients, these mythical creatures represented fearful stimuli that were associated with distant unknown territories inhabited by uncanny creatures.

Whereas fossil remains and unexplained natural events might help to explain the origin of mythological creatures (Mayor, 2001; Kaplan, 2012), along with responses such as fear and anxiety (also see Asma, 2009), the mechanisms that support the retention of these creatures in the modern mind requires further explanation (e.g., Barrett and Keil, 1996). Similar to the uncanny valley studies investigating categorization, studies of religious beliefs assume that belief in such ontological categories is a result of humans using existing cognitive templates that have exceptional features (Boyer, 1993, 2001). A heightened sensitivity to these anomalous stimuli, or so-called "counterintuitive beliefs" (Boyer and Ramble, 2001; Atran and Norenzayan, 2004), could be a result of increases in negative affect associated with the uncanny valley. These results can be related back to the idea of distinctiveness in memory (e.g., Hunt and Worthen, 2006), wherein the dissimilarity of an item within a given context facilitates the encoding and retrieval of stimuli. The uncanny valley could also have implications for recall that facilitates the cultural transmission of knowledge. As in the case of food taboos, such a negative valence might reduce our willingness to interact with features of our environment, thereby further reducing our exposure to a range of stimuli. An item's distinctiveness in memory can thereby compound an initial aversive response. Modern equivalents are also evidenced in genetically modified organisms that antagonist interest groups have labeled "Frankenfoods," such as the transgenic tomato, which has been engineered with a gene from the winter flounder that makes it tolerant to freezing temperatures. Such rhetorical devices are clearly predicated on a fear of novel hybrid organisms.

\section{Human categories and out-group bias}

A final form of cross-cultural evidence for uncanny valley-like phenomena is the perception of human groups. Much like some non-human categories, unfamiliar human groups might be construed as distinct species. For instance, Gil-White (2001) suggests that this could in fact be the case for ethnicities. Identifying a race as "sub-human" implicitly or explicitly can be understood in these terms. For instance, a low-frequency of exposure to outgroup members, or explicitly transmitted out-group biases, could create negative affective responses to features associated with these individuals (for the effect of stimulus frequency on affect, see Zajonc, 1968; Bornstein, 1989). Though controversial, numerous studies have found evidence for implicit negative associations with minority groups (Greenwald et al., 2009), which can be contrasted against explicit biases to "lower" social classes, and castes associated with "untouchability," contamination, and food taboos (Harper, 1964). Accounts of early explorers encountering new tribes and peoples for the first time are also consistent with this possibility (e.g., Hall, 1992). Prophylactic measures were taken when entering strange lands inhabited by others and ritual purification following contact was needed to "guard against... the magical arts of its inhabitants" (Frazer, 1922, p. 110; see also Douglas, 1966/2002). For these explorers, the people that they encountered were similar to them but the comparatively small differences in terms of physical and cultural variation produced strong negative affective responses. As Hall (1992) notes of travelers' tales, features of out-group members were sometimes even perceived to reflect a blending of human and non-human animal traits: "In the land of Indian there are men with dogs' heads." (quoted in Newby, 1975, p. 17).

A large degree of variation is also observed in the number and nature of reified gender and sexual categories across societies. Early First Nations societies in North America often recognized three or more sexes or genders and their associated roles within the society (Herdt, 1994). In sharp contrast, the early definition of homosexuality as a disorder in North American psychiatry reflects a perceived "deviation" from socially defined categories (Zucker, 2005). In the context of the present review, the experiences of homosexual, bisexual, and transgendered persons could reflect their status as a covert category in contemporary North American society. For instance, as described in a report by the San Francisco Human Rights Commission (2011), the experiences of bisexuals include being "rendered invisible" and being seen as vectors for the spread of sexually-transmitted diseases. Similar claims could be made concerning the historic status of women in Western and Near Eastern societies. For example, the unitary gender structure in the mythology of Abrahamic religions that sees Eve created from Adam's rib, framed the female sex as a derivative of the male sex. When framed in terms of deviation from a male reference category, the uncanny valley might offer a plausible basis for explaining negative affect and discrimination toward women. While exposure to male and female exemplars should be present in a society with nearly equal frequency, sociocultural practices can limit 
the exposure that one sex and gender has to another. While frequency alone is unlikely to account for all sex and gender biases, inasmuch as it does make a contribution it would support the existence of an uncanny valley. An understanding of the conditions in which the uncanny valley occurs, and whether increased exposure to low-frequency or negative-valence categories buffers against it, could facilitate our understanding of intergroup conflicts, and how they can be minimized. The codification of third or multiple gender categories minimally suggests that this is possible.

\section{CONCLUDING REMARKS}

Considered individually, folkbiological categories, biological anomalies and monsters, as well as human categories represent individual cultural products of human categorization. Instead, we suggest that the uncanny valley might reflect a primary response to unfamiliar or covert categories. In the absence of having prior knowledge of an individual or group, the relative distinctiveness of a category, due to a lower frequency of exposure, will produce negative affect-an inversion of the mere-exposure effect. The deceptive simplicity of learning mechanisms can lead to important individual and social consequences. If the uncanny valley and its relation to negative affect is a result of frequency of exposure, then its amelioration can be facilitated by increasing the frequency of the target stimuli within the environment. The few studies that have considered the relationship between familiarity, discriminability, and affect (Cheetham et al., 2013, 2014; Burleigh and Schoenherr, 2014) need to be complimented with more research that systematically manipulates the features of the ontological categories used for comparison.

\section{REFERENCES}

Asma, S. T. (2009). On Monsters: An Unnatural History of our Worst Fears. Oxford: Oxford University Press.

Atran, S. (1983). Covert fragmenta and the origins of the botanical family. Man 18, 51-71. doi: $10.2307 / 2801764$

Atran, S., and Norenzayan, A. (2004). Religion's evolutionary landscape: counterintuition, commitment, compassion, communion. Behav. Brain Sci. 27, 713-770. doi: 10.1017/S0140525X04 000172
Barrett, J. L., and Keil, F. C. (1996). Conceptualizing a nonnatural entity: anthropomorphism in god concepts. Cogn. Psychol. 31, 219-247. doi: 10.1006/cogp.1996.0017

Berlin, B. (1974). Further notes on covert categories and folk taxonomies: a reply to Brown. Am. Anthropol. 76, 327-331. doi: 10.1525/aa.1974.76.2. 02a00080

Berlin, B., Breedlove, D. E., and Raven, P. H. (1968). Covert categories and folk taxonomies, Am. Anthropol. 70, 290-299. doi: 10.1525/aa.1968. 70.2.02a00050

Bornstein, R. F. (1989). Exposure and affect: overview and meta-analysis of research, 1968-1987. Psychol. Bull. 106, 265-289. doi 10.1037/0033-2909.106.2.265

Boyer, P. (1993). Cognitive Aspects of Religious Symbolism. Cambridge: Cambridge University Press.

Boyer, P. (2001). Religion Explained: The Evolutionary Origins of Religious Thought. New York, NY: Basic Books.

Boyer, P., and Ramble, C. (2001). Cognitive templates for religious concepts: cross-cultural evidence for recall of counter-intuitive representations. Cogn. Sci. 25, 535-564. doi: 10.1207/ s15516709cog2504_2

Brown, C. H. (1974). Unique beginners and covert categories in folk biological taxonomies. Am. Anthropol. 76, 325-327. doi: 10.1525/aa.1974.76.2.02a00070

Burleigh, T. J., and Schoenherr, J. R. (2014). A reappraisal of the Uncanny Valley: categorical perception or frequency-based sensitization? Front. Psychol. 5:1488. doi: 10.3389/fpsyg.2014.01488

Cheetham, M., Pavlovic, I., Jordan, N., Suter, P., and Jancke, L. (2013). Category processing and the humanlikeness dimension of the Uncanny Valley Hypothesis: eye-tracking data. Front. Psychol. 4:108. doi: 10.3389/fpsyg.2013. 00108

Cheetham, M., Suter, P., and Jancke, L. (2014). Perceptual discrimination difficulty and familiarity in the Uncanny Valley: more like a "Happy Valley." Front. Psychol. 5:1219. doi: 10.3389/fpsyg.2013. 01219

Douglas, M. (1957). Animals in Lele religious symbolism. Afr. J. Int. Afr. Inst. 27, 46-58. doi: $10.2307 / 1156365$

Douglas, M. (1966/2002). Purity and Danger: An Analysis of Concepts of Pollution and Taboo. London: Routledge \& Kegan Paul. doi: 10.4324/9780203361832

Frazer, J. G. (1922). The Golden Bough: A Study in Magic and Religion. New York, NY: Macmillan. (Original work published 1890).

Gil-White, F. (2001). Are ethnic groups biological "species" to the human brain? Curr. Anthropol. 42, 515-554. doi: 10.1086/321802

Greenwald, A. G., Poehlman, T. A., Uhlmann, E. L. and Banaji, M. R. (2009). Understanding and using the implicit association test: III. Meta-analysis of predictive validity. J. Pers. Soc. Psychol. 97, 17-41. doi: $10.1037 / \mathrm{a} 0015575$

Hall, S. (1992). "The west and the rest: discourse in power," in The Indigenous Experience: Global Perspectives, eds R. C. A. Maaka and C. Andersen (Toronto: Canadian Scholars' Press Inc.), 165-173.

Harper, E. B. (1964). Ritual pollution as an integrator of caste and religion. J. Asian Stud. 23, 151-197. doi: $10.2307 / 2050627$
Haxby, J. V., Hoffman, E. A., and Gobbini, M. I. (2002). Human neural systems for face recognition and social communication. Biol. Psychiatry 51, 59-67. doi: 10.1016/S0006-3223(01) 01330-0

Henrich, J., and Henrich, N. (2010). The evolution of cultural adaptations: Fijian food taboos protect against dangerous marine toxins. Proc. $R$. Soc. $B$ 277, 3715-3724. doi: 10.1098/rspb.2010. 1191

Herdt, G., (ed.). (1994). Third Sex, Third Gender: Beyond Sexual Dimorphism in Culture and History. New York: Zone Books.

Hunt, R. R., and Worthen, J. (2006). Distinctiveness and Memory. New York, NY: Oxford University Press. doi: 10.1093/acprof:oso/9780195169669.0 01.0001

Kaplan, M. (2012). Medusa's Gaze and Vampire's Bite: The Science of Monsters. New York, NY: Scribner.

Lewkowicz, D. J., and Ghazanfar, A. (2012). The development of the uncanny valley in infants. Dev. Psychobiol. 54, 124-32. doi: 10.1002/dev. 20583

Mayor, A. (2001). The First Fossil Hunters: Paleontology in Greek and Roman Times. Princeton: Princeton University Press.

Mayor, A. (2005). Fossil Legends of the First Americans. Princeton, NJ: Princeton University Press.

Medin, D. L., Lynch, E. B., Coley, J. D., and Atran, S. (1997). Categorization and reasoning among tree experts: do all roads lead to Rome? Cogn. Psychol. 32, 49-96. doi: 10.1006/cogp.1997.0645

Mori, M. (1970). The uncanny valley. Energy 7, 33-35.

Moscovici, S. (1981). "On social representations," in Social Cognition: Perspectives on Everyday Understanding, ed J. P. Forgas (London: Academic Press), 181-209.

Newby, E. (1975). The Mitchell Beazley World Atlas of Exploration. London: Mitchell Beazley.

Rosch, E., Mervis, C. B., Gray, W. D., Johnson, D. M., and Boyes-Braem, P. (1976). Basic objects in natural categories. Cognit. Psychol. 8, 382-439.

San Francisco Human Rights Commission. (2011). Bisexual Invisibility: Impacts and Recommendations. Available online at: http://sfhrc.org/sites/sf-hrc.org/files/migrated/FileCenter/ Documents/HRC_Publications/Articles/Bisexual_ Invisiblity_Impacts_and_Recommendations_ March_2011.pdf

Sperber, D. (1996). Why are perfect animals, hybrids, and monsters food for symbolic thought? Method Theory Study Relig. 8, 143-169. doi: 10.1163/157006896X00170

Sperber, D., and Hirschfeld, L. A. (2004). The cognitive foundations of cultural stability and diversity. Trends Cogn. Sci. 8, 40-46. doi: 10.1016/j.tics.2003.11.002

Tanaka, J., and Taylor, M. (1991). Object categories and expertise: is the basic level in the eye of the beholder? Cognit. Psychol. 23, 457-482.

Zajonc, R. B. (1968). Attitudinal effects of mere exposure. J. Pers. Soc. Psychol. 9, 1-27. doi: $10.1037 / \mathrm{h} 0025848$

Zucker, K. J. (2005). Was the Gender Identity Disorder of childhood diagnosis introduced into DSM-III as a backdoor maneuver to replace homosexuality? A historical note. J. Sex Marital Ther. 31, 31-42. doi: 10.1080/009262305904 75251 
Conflict of Interest Statement: The authors declare that the research was conducted in the absence of any commercial or financial relationships that could be construed as a potential conflict of interest.

Received: 10 June 2014; accepted: 28 November 2014; published online: 21 January 2015.
Citation: Schoenherr JR and Burleigh TJ (2015) Uncanny sociocultural categories. Front. Psychol. 5:1456. doi: 10.3389/fpsyg.2014.01456

This article was submitted to Cognitive Science, a section of the journal Frontiers in Psychology.

Copyright (C) 2015 Schoenherr and Burleigh. This is an open-access article distributed under the terms of the Creative Commons Attribution License
(CCBY). The use, distribution or reproduction in other forums is permitted, provided the original author(s) or licensor are credited and that the original publication in this journal is cited, in accordance with accepted academic practice. No use, distribution or reproduction is permitted which does not comply with these terms. 